\title{
FIEBRE MANCHADA Y SU POTENCIAL COINFECCIÓN CON OTRAS ENFERMEDADES TRANSMITIDAS POR VECTOR
}

\author{
Spotted fever and its potential coinfection \\ with other vector borne diseases
}

\section{EPISTEMUS}

ISSN: 2007-8196 (electrónico)

ISSN: 2007-4530 (impresa)

Dr. Gerardo Álvarez Hernández ${ }^{1}$

Dr. Jesús David Licona Enríquez ${ }^{2}$

Dr. Jesús Delgado de la Mora ${ }^{3}$

Dra. María del Carmen Candia Plata 4

Recibido: 27 de noviembre de 2016 ,

Aceptado: 22 de mayo de 2017

Autor de Correspondencia:

Dr. Gerardo Álvarez Hernández

Correo:galvarezh63@gmail.com

\section{Resumen}

La fiebre manchada por Rickettsia rickettsii (FMRR) es una enfermedad reemergente transmitida en México por las garrapatas Rhipicephalus sanguineus infectadas por la bacteria homónima. Presentamos 3 casos fatales que cumplieron con criterios de compatibilidad para FMRR, y que al tener un resultado positivo para Dengue o Chikungunya no se solicitó prueba confirmatoria para FMRR o se hizo en días de evolución clínica donde es poco probable encontrar elevación de anticuerpos específicos contra la bacteria. Si bien existe una similitud en el cuadro clínico y de laboratorio entre FMRR y padecimientos febriles exantemáticos endémicos en Sonora, hay datos clínicos, de laboratorio y epidemiológicos que podrían guiar al médico clínico a sospechar de la enfermedad, incluso en presencia de una prueba positiva confirmatoria de algún otro padecimiento. Esta serie de casos es una llamada a estructurar protocolos de estudio en pacientes con enfermedades febriles exantemáticas en regiones endémicas de FMRR como Sonora.

Palabras claves: Rickettsia rickettsii, Dengue, Fiebre Chikungunya.

\begin{abstract}
Rocky Mountain Spotted Fever (RMSF) is a reemergent disease in Mexico transmitted by Rhipicephalus sanguineus ticks infected with Rickettsia rickettsii bacteria. We present 3 fatal cases that met clinical criteria for RMSF but did not have a confirmatory test due to having a positive test for Dengue or Chikungunya infection or because the test was done in a clinical period where is unlikely to find a rise of specific antibodies against the bacteria. Although there is similarity in clinical and laboratory findings between RMSF and other exanthematic febrile diseases endemic to Sonora, there are clinical, laboratory and epidemiological clues that can guide clinicians to an early suspicion of the disease, even in the presence of a positive confirmatory result for other diseases. This case series is a call to improve study protocols on patients with exanthematic febrile diseases in endemic regions for RMSF such as the State of Sonora
\end{abstract}

Key words: Rickettsia rickettsii, Dengue, Chikungunya Fever.

1 Departamento de Medicina y Ciencias de la Salud, Universidad de Sonora, México. / Correo: galvarezh63@gmail.com

2 Departamento de Medicina y Ciencias de la Salud, Universidad de Sonora, México. / Correo: jdliconae@gmail.com

3 Departamento de Medicina y Ciencias de la Salud, Universidad de Sonora, México. / Correo: jdelgadom@live.com.mx

4 Departamento de Medicina y Ciencias de la Salud, Universidad de Sonora, México. / Correo: carmenc@guayacan.uson.mx 


\section{INTRODUCCIÓN}

La Fiebre Manchada por Rickettsia rickettsii (FMRR) es una enfermedad transmitida en México por las garrapatas Rhipicephalus sanguineus infectadas con Rickettsia rickettsii, una bacteria gran negativa intracelular obligada [1-3], reemergente en el estado de Sonora desde los primeros años del siglo XXI como un problema de salud pública con un impacto específico en grupos vulnerables de la población [4].

Su importancia radica en que a pesar de la existencia de un tratamiento antibiótico efectivo, la letalidad en Sonora permanece entre las más elevadas a nivel mundial, principalmente asociada al retraso diagnóstico y terapéutico, tanto por la poca especificidad sintomática en los primeros días de evolución como por el desconocimiento médico y por la ocurrencia de enfermedades que semejan el cortejo sintomático de la FMRR, como son el Dengue (DenV), Chikungunya (ChikV), Zika (ZikV), hepatitis, entre otros [4-8]. Por ello, el médico en contacto con pacientes infectados por FMRR, enfrenta un desafío diagnóstico, pues tales padecimientos comparten con la FMRR no sólo el cuadro clínico y de laboratorio, si no también ocurre con mayor frecuencia en escenarios sociodemográficos (p.e. pobreza, contacto con perros, garrapatas y mosquitos) y climáticos (Verano) que son semejantes [9-10].

Si bien, el impacto de un algoritmo de abordaje médico en enfermedades febriles exantemáticas en regiones con FMRR no ha sido documentado, en áreas con condiciones climáticas similares a las de Sonora, se ha reportado una subestimación de diversas enfermedades que se atribuye a resultados positivos mediante pruebas rápidas yserológicas para DenV, lo que puede confundir al médico y detener el protocolo de estudio al no considerarse la posibilidad de una coinfección [11], y en el caso de regiones con FMRR, elevar las tasas de letalidad al contribuir al retraso del tratamiento específico con doxiciclina.

Por lo anterior, presentamos una serie de casos hospitalizados compatibles por criterios clínicos y epidemiológicos con el diagnóstico de FMRR, en los que adicionalmente se identificó una prueba positiva a Dengue o Chikungunya. Se discuten las implicaciones de la potencial coinfección.

\section{REPORTE DE CASOS}

\section{Caso 1}

Paciente masculino de 26 años de edad, sin antecedentes patológicos de importancia, historia de contacto con perros o garrapatas y previamente sano. Inició su sintomatología 4 días previos a su hospitalización con astenia, adinamia, mialgias, artralgias, vómito, diarrea, dolor abdominal, exantema petequial generalizado y fiebre no cuantificada. Acudió previamente a consulta con médico particular que prescribió manejo sintomático no especificado antes de su ingreso.

A la exploración física se le observó con exantema generalizado petequial que involucraba palmas y plantas, con deshidratación de piel y mucosas e inyección conjuntival bilateral. Sus signos vitales mostraban una presión arterial de $80 / 60 \mathrm{mmHg}$, frecuencia cardiaca de 133 latidos por minuto y una temperatura de $36.3^{\circ} \mathrm{C}$, sin agregados patológicos a la exploración. Sus pruebas

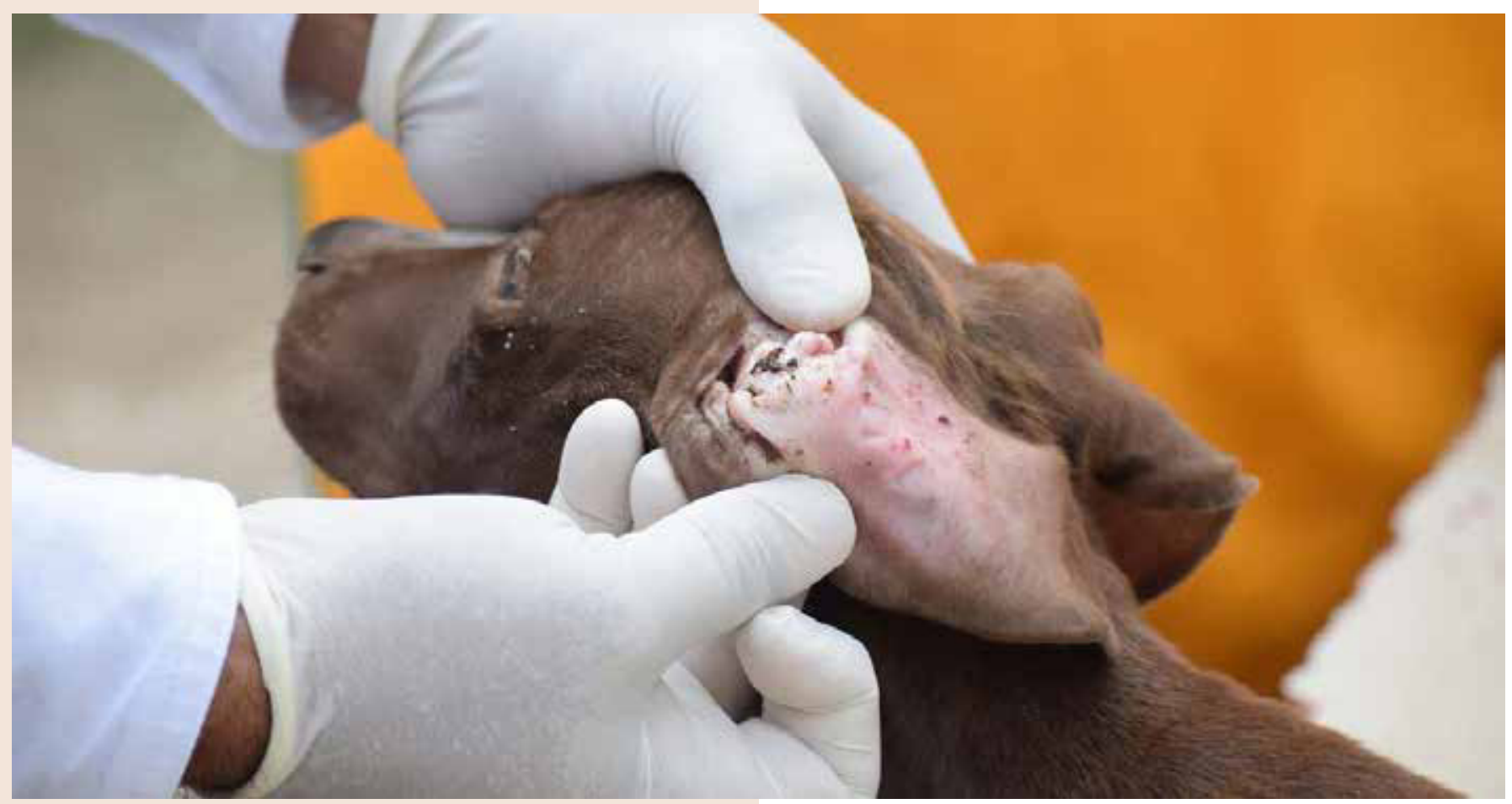




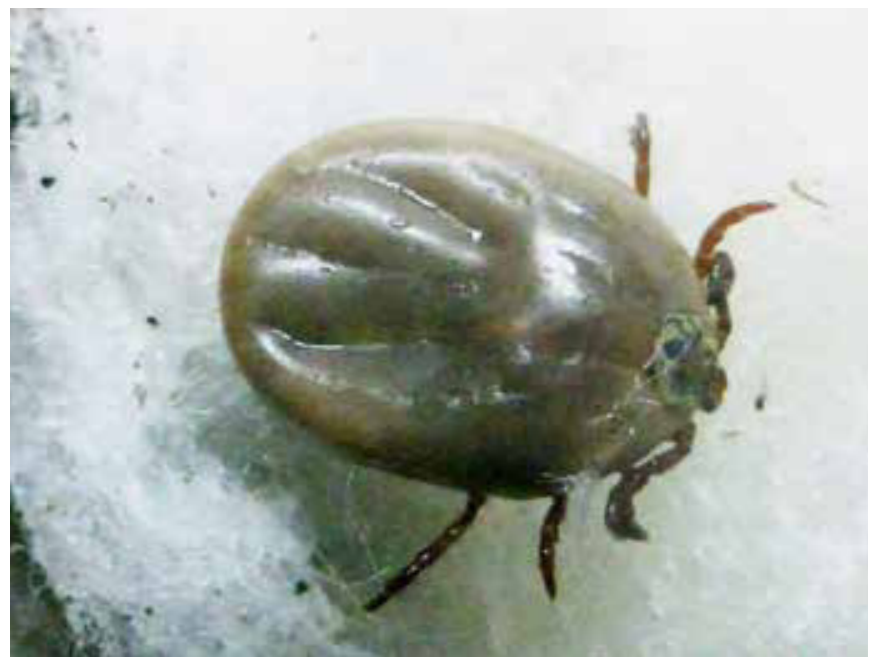

de laboratorio mostraron leucocitosis $(18.6 / \mu \mathrm{L})$ con predominio de neutrófilos $(17.5 / \mu \mathrm{L})$, linfopenia $(0-7 / \mu \mathrm{L})$, plaquetopenia severa $(14 / \mu \mathrm{L})$, hiponatremia $(126 \mathrm{mEq} / \mathrm{L})$, hipoalbuminemia $(2.6 \mathrm{gr} / \mathrm{dL})$ y procalcitonina sérica elevada $(18 \mathrm{ng} / \mathrm{mL})$; se le realizó un ultrasonido abdominal que mostró escaso derrame pleural izquierdo.

A su ingreso fue diagnosticado como enfermedad febril exantemática y se sospechó de rickettsiosis por lo que se inició manejo con doxiciclina intravenosa (IV). También, se dio reanimación hídrica con soluciones cristaloides sin presentar mejoría, por lo que se brindó apoyo aminérgico, además de transfundirse seis concentrados plaquetarios debido a plaquetopenia severa. A pesar del manejo, se mantuvo febril con hipotensión, taquicardia y oliguria, por lo que en su segundo día de estancia intrahospitalaria fue ingresado a la Unidad de Cuidados Intensivos (UCI) debido

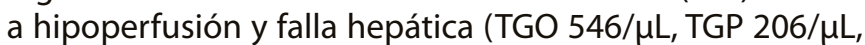
GGT 258/ $\mu \mathrm{L}$ ), renal (Creatinina $1.49 \mathrm{mg} / \mathrm{dL}$, Urea $90 \mathrm{mg} /$ $\mathrm{dL}$ ), hematológica y hemodinámica, que provocó una falla orgánica múltiple y la defunción. Se obtuvo un resultado positivo para DenV (NS1), pero no se realizó examen serológico para FMRR debido a que sólo tenía 4 días de evolución al momento de su ingreso.

\section{Caso 2}

Paciente femenino de 35 años de edad con 3 cesáreas previas, historia de contacto con perros ectoparasitados y con el antecedente de que dos contactos intradomiciliarios fueron confirmados (PCR positivo) como casos de fiebre manchada por Rickettsia rickettsii, con tres días de diferencia. Tenía historia de asma desde la infancia tratada únicamente con medicamento de rescate. Inició su padecimiento 1 semana previa a su ingreso con mialgias, artralgias, cefalea e hipertermia no cuantificada. Dos días antes de su ingreso inició exantema petequial generalizado con predominio en extremidades inferiores. Acudió a médico general que estableció el diagnóstico de dengue no grave y fue administrado tratamiento sintomático (paracetamol). Sin mejoría, se agregó hemorragia transvaginal sin relación con su ciclo menstrual y disnea en reposo, por lo que fue hospitalizada.

A su ingreso hospitalario se observó somnolienta, con piel marmórea y presencia de exantema petequial que involucró palmas y plantas, así como mucosas deshidratadas. En tórax se auscultó hipoventilación con presencia de estertores crepitantes, llenado capilar retardado en extremidades superiores e inferiores, pulsos no perceptibles, signos vitales con tensión arterial imperceptible, frecuencia cardiaca de 120 latidos por minuto, frecuencia respiratoria de 6 respiraciones por minuto y glicemia capilar de $25 \mathrm{mg} / \mathrm{dL}$. En el laboratorio tenía leucocitos de $9.7 / \mu \mathrm{L}$, con predominio de neutrófilos $(7.8 / \mu \mathrm{L})$, plaquetopenia severa $(6 / \mu \mathrm{L})$, falla renal (creatinina $3.07 \mathrm{mg} / \mathrm{dL}$, urea $91 \mathrm{mg} / \mathrm{dL}$ ), falla hepática (TGO 1720/ $\mu \mathrm{L}$,

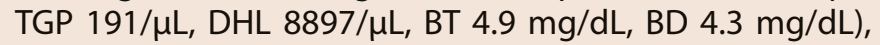
hiponatremia (131 mEq/L) e hiperkalemia (incremento de potasio) $(8.39 \mathrm{mEq} / \mathrm{L})$.

Se dio manejo avanzado de la vía aérea con intubación endotraqueal en secuencia rápida, tuvo sangrado endotraqueal de $400 \mathrm{ml}$ y paro cardiorrespiratorio irreversible apenas un par de horas posteriores a su ingreso. Se obtuvo resultado positivo para DenV (NS1) e indeterminado para FMRR en una prueba de inmunofluorescencia indirecta (IgG) que se realizó a una muestra sanguínea única tomada al séptimo día de evolución.

\section{Caso 3}

Paciente masculino de 39 años de edad, previamente sano y sin antecedentes patológicos de importancia, inició síntomas 4 días previos a su ingreso con mialgias, artralgias, hipertermia no cuantificada, así como odinofagia y disfagia, fue tratado ambulatoriamente como infección de vías respiratorias altas, sin especificar tratamiento. Sin mejoría, se agregó edema de miembros inferiores y tronco, así como exantema petequial generalizado con coloración marmórea de la piel y dolor intenso en articulaciones de pies y manos que refirió como incapacitante además de disnea en reposo.

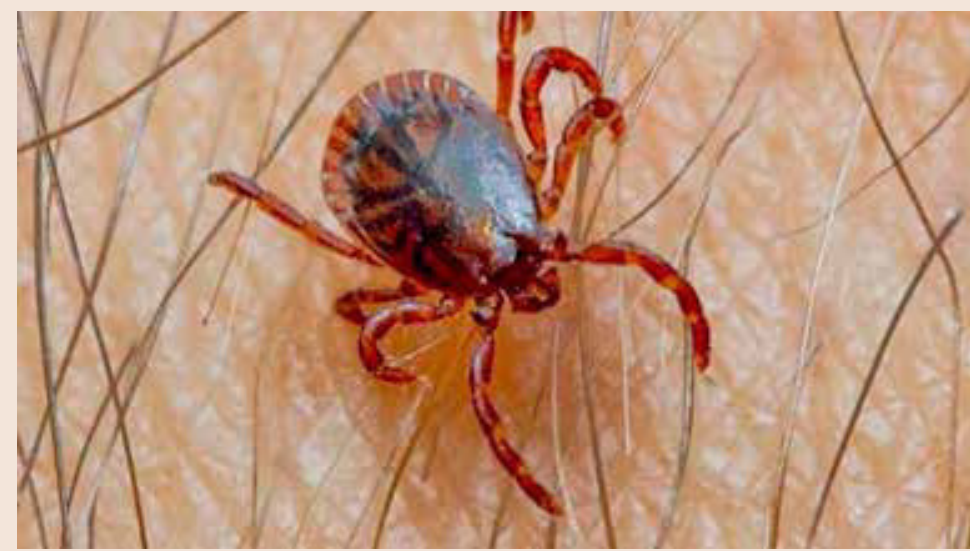




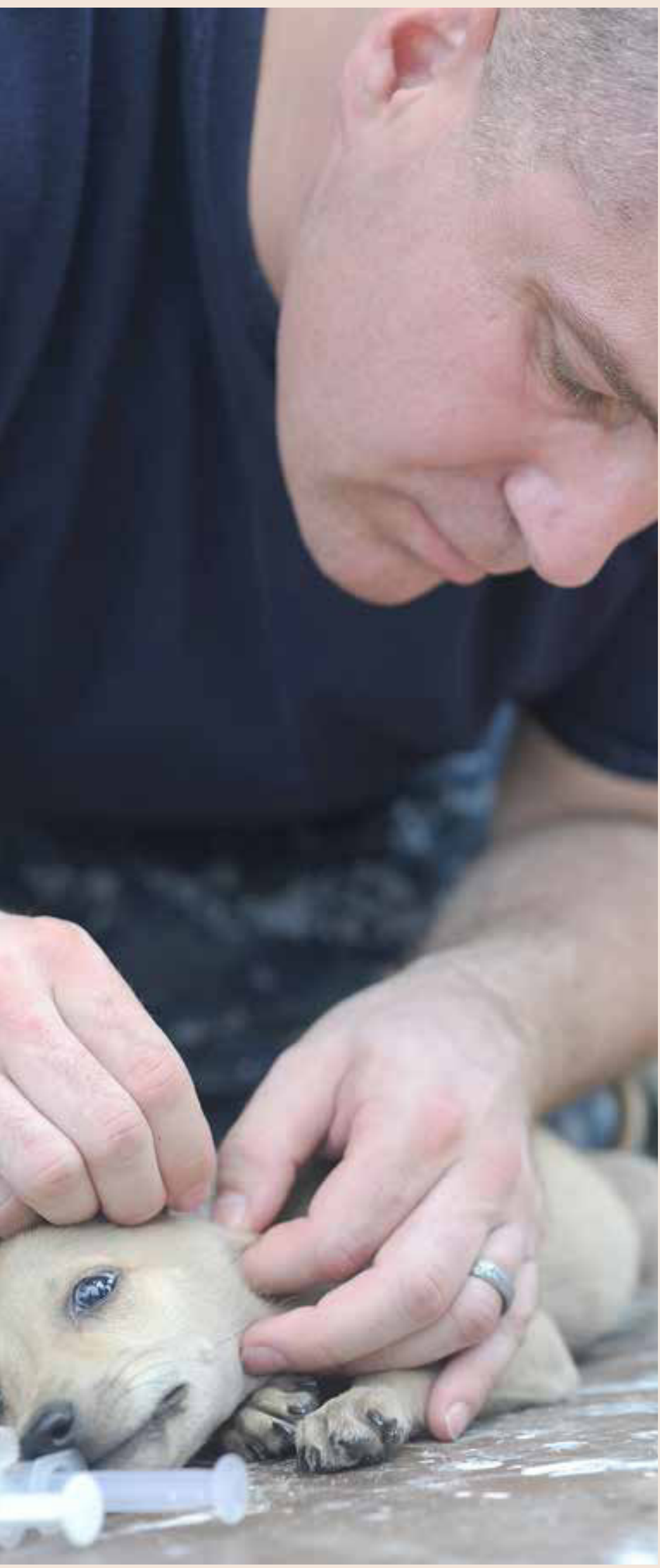

Acudió a urgencias donde fue ingresado con datos de hipoperfusión con falla renal y hepática, siendo diagnosticado como probable rickettsiosis y se inició manejo con doxiciclina IV, así como reanimación con soluciones cristaloides. Los laboratorios al ingreso mostraron una leucocitosis $(48.28 / \mu \mathrm{L})$ caracterizada por linfopenia $(0.38 / \mu \mathrm{L})$, plaquetopenia severa $(43 / \mu \mathrm{L})$, hemoconcentración (hemoglobina $20.2 \mathrm{~g} / \mathrm{dL}$, hematocrito $56.3 \%)$, hiponatremia $(133.8 \mathrm{mEq} / \mathrm{L})$, hiperkalemia $(8.0$ $\mathrm{mEq} / \mathrm{L}$ ), falla renal (creatinina $2.8 \mathrm{mg} / \mathrm{dL}$, urea $64 \mathrm{Mg} / \mathrm{dL}$ ) y datos de falla hepática (TGO 348/ $\mu \mathrm{L}$, TGP $62 / \mu \mathrm{L}$, GGT

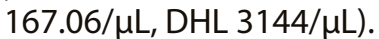

Sin presentar mejoría clínica, fue admitido a la unidad de cuidados intensivos $(\mathrm{UCl}$ ) en su segundo día de estancia intrahospitalaria donde continuó sin responder a tratamiento con líquidos y aminas, persistiendo con hipotensión y anuria, presentó paro cardiorrespiratorio irreversible por lo que se declaró su defunción. Se confirmó diagnóstico de ChikV por reacción en cadena de polimerasa $(P C R)$, pero no se realizó prueba para FMRR.

\section{DISCUSIÓN}

La fiebre manchada por Rickettsia rickettsii es un padecimiento difícil de confirmar por laboratorio y su diagnóstico es esencialmente clínico. La prueba de referencia que confirma es la determinación cuantitativa de anticuerpos IgG en muestras pareadas tomadas al final de la primera y de la tercera semana de evolución clínica [2]. Los síntomas y signos, especialmente el exantema petequial generalizado que involucra plantas y palmas, la presencia de neutrofilia con linfopenia e hiponatremia, así como los datos epidemiológicos (p.e. contacto con perros, casos confirmados en misma familia) son altamente sugestivos de FMRR. También es esencial considerar que las tasas de letalidad para DenV/ChikV son bajas, mientras en FMRR predomina en pacientes con comorbilidades (p.e. insuficiencia renal, deficiencia de glucosa 6 fosfato deshidrogenasa) $[4,12]$, aunque esto no fue observado en los casos que hemos descrito quienes se encontraban aparentemente sanos antes de su última oportunidad.

Basados en lo anterior, los casos revisados cumplieron con criterios de compatibilidad para FMRR. Al obtener un resultado positivo para dengue o chikungunya, no se solicitó prueba para $R$. rickettsii o se hizo en días en los que es poco probable determinar la elevación de anticuerpos, ya que se ha documentado que sólo del 40$50 \%$ de los pacientes elevan títulos después del $7^{\circ}-9^{\circ}$ día de las manifestaciones clínicas, y aun cuando se obtuviera un resultado positivo, es necesaria la realización de una segunda prueba para evidenciar la elevación de 4 veces los títulos de IgG para confirmar el diagnóstico de FMRR [13].

Si bien existe una similitud en el cuadro clínico y de laboratorioentreFMRRydiversos padecimientosendémicos en Sonora como dengue, chikungunya y zika, la presencia de fiebre, cefalea y malestar general, acompañados por 


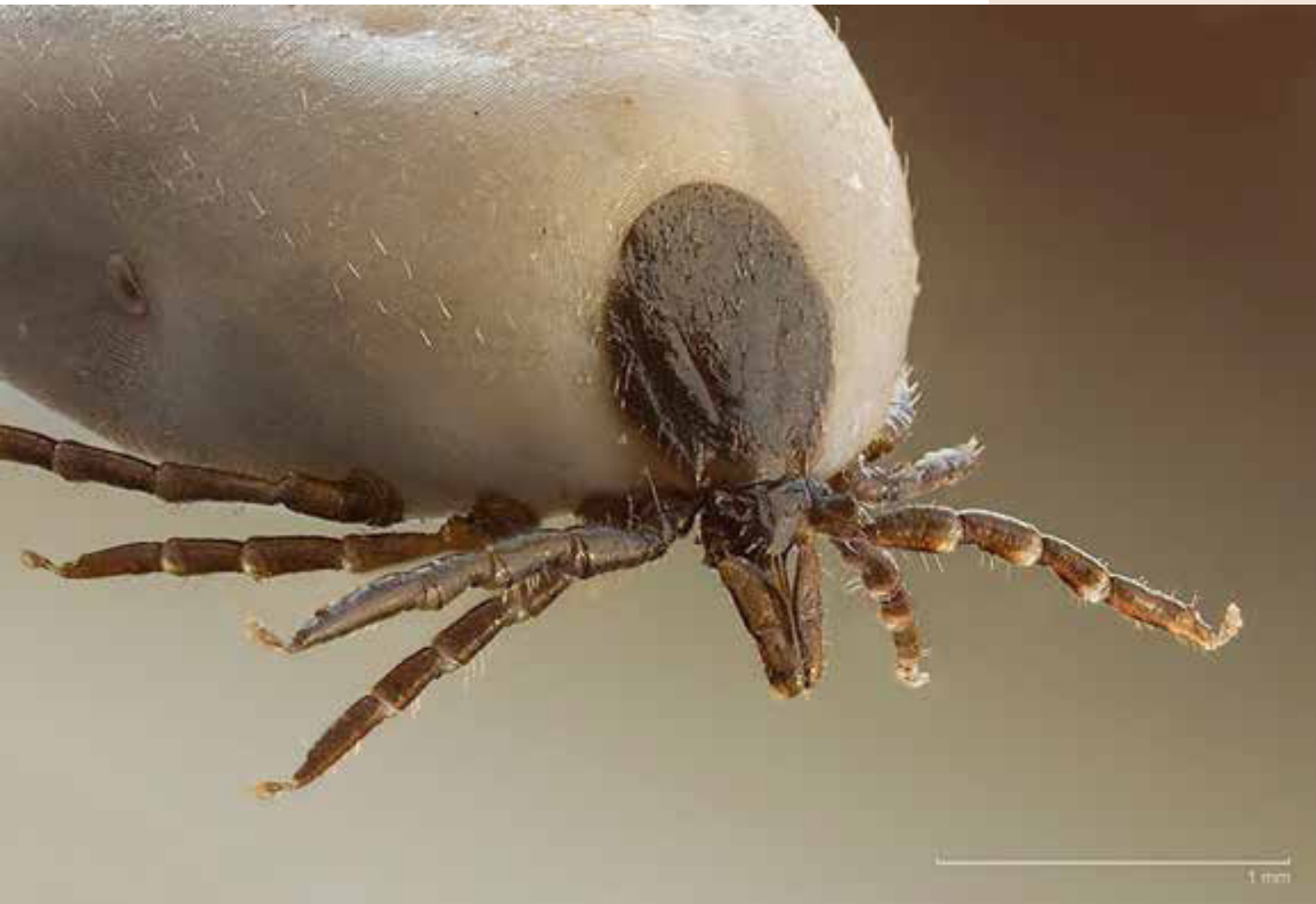

Si bien el exantema puede ser un signo que ayude a sospechar alguna de estas enfermedades, es posible que no se manifieste $o$ no se logre identificar, particularmente en pacientes de piel oscura. Además del exantema existen otros síntomas característicos como las artralgias severas de pequeñas articulaciones en el caso de ChikV y el dolor retroocular en el caso de DenV, aunque es complicado basar la sospecha diagnóstica en estos datos dada la subjetividad de los mismos $[9,15]$.

En el caso de datos de laboratorio, aunque la trombocitopenia es una constante dentro de estas enfermedades, en ChikV y ZikaV el descenso plaquetario es menor e incluso no hay trombocitopenia $[10,15]$. Del mismo modo, el conteo leucocitario resulta relevante, en el caso de FMRR se

historia de contacto con garrapatas podrían guiar al médico a sospechar FMRR, cuyo diagnóstico no debe descartarse aún en presencia de alguna prueba confirmatoria de otro padecimiento (DenV, ChikV). La presencia de exantema puede constituir un elemento clave en la sospecha diagnóstica. Aunque se acepta que hasta $10 \%$ de los pacientes con FMRR no presentan exantema, cuando lo tienen es inicialmente macular que puede evolucionar a petequias generalizadas, y en fases avanzadas de la vasculitis involucra característicamente plantas y palmas. El exantema de FMRR tiene una progresión centrípeta desde las muñecas y tobillos hacia los brazos, piernas y tronco [2, $3,14]$. También es importante considerar que el exantema en FMRR puede ocurrir hasta el $4-5^{\circ}$ día de evolución, aunque como se señaló no es necesaria su aparición para iniciar el tratamiento antibiótico $[2,14,18]$.

En el caso de ChikV, el exantema se caracteriza por ser macular sin respetar plantas ni palmas, similar al exantema de FMRR, pero sin evolucionar a petequial, además en pacientes pediátricos y adultos con cuadros severos se han reportado lesiones bulosas $[15,16]$. En pacientes con dengue durante la fase febril, se describe un exantema maculo-papular, eritematoso, que no afecta plantas y palmas, mientras que en la fase de recuperación se puede presentar un segundo evento exantemático de tipo maculopapular o petequial generalizado que suele acompañarse de prurito $[9,17]$. Por otro lado, en el caso de zika aunque no hay claridad acerca de las características del exantema, es usualmente maculo-papular, rubicundo y acompañado de purito. han documentado tanto leucocitosis como leucopenias acompañadas de neutrofilia y linfopenia [4, 19]; ChikV por su parte suele manifestarse con cuentas leucocitarias bajas sin diferencias sustantivas en el conteo, aunque en casos severos se ha reportado casos leucocitosis y neutrofilia [20], en el caso de DenV la leucopenia es constante sin predominio en el conteo diferencial [9].

A pesar de identificarse algunos otros datos de laboratorio sugerentes de cada enfermedad, como la hiponatremia en FMRR o la hipocalcemia en ChikV, pueden ocurrir en los tres padecimientos, igual que la hipoalbuminemia, elevación de enzimas hepáticas y bilirrubinas, prolongación de tiempos de coagulación, elevación de cuerpo azoados, entre otros [4, 9, 15]. Asimismo, basados en que procalcitonina (PCT) es un reactante de fase aguda que se eleva principalmente en infecciones de tipo bacteriano, puede constituir un marcador biológico útil, especialmente ante la presencia de cuadro exantemático febril, debe incluirse el diagnóstico de sospecha de FMRR [20-22].

A pesar de no encontrarse un dato de laboratorio patognomónico, la presencia de trombocitopenia con leucocitosis puede sugerir un cuadro de gravedad de FMRR, por lo que es necesario la evaluación médica cuidadosa que compare el cuadro clínico y de laboratorio de las 3 patologías descritas en esta serie. Del mismo modo, en regiones endémicas de FMRR, dengue y chikungunya, resulta prioritario establecer un protocolo de estudio de enfermedades febriles exantemáticas. En este sentido, es menester considerar que las pruebas rápidas para DenV 
pueden generar un subregistro de otras enfermedades con presentaciones similares (ChikV, Zika) [11], y en el caso de regiones con FMRR, retrasar la sospecha diagnóstica e incrementar la probabilidad de formas severas al detenerse la indagación clínica cuando se obtenga un resultado positivo por prueba rápida para DenV.

Existe el antecedente de un paciente coinfectado con Rickettsia rickettsii y Streptococcus pyogenes, que presentó un cuadro clínico agresivo, en el que a pesar de haber iniciado doxiciclina en su $4^{\circ}$ día de evolución, el paciente continuó con deterioro generalizado y falleció en su $5^{\circ}$ día de evolución [23]. Este antecedente sugiere que la coinfección de FMRR con otros padecimientos es posible, aun cuando no tenemos conocimiento de la confirmación de la coinfección por FMRR y DenV/ChikV. Nuestra serie no pretende concluir al respecto, sino sugerir que se realicen protocolos exhaustivos de evaluación clínica y de laboratorio en pacientes con exantema febril en regiones endémicas semejantes a las que se observan en el estado de Sonora.

\section{REFERENCIAS}

[1] Dantas-Torres F. Rocky Mountain spotted fever. Lancet Infect Dis 2007; 7(11): 724-32.

[2] Chen LF, Sexton DJ. What's new in Rocky mountain spotted fever? Infect Dis Clin North Am 2008; 22(3): 415-432.

[3] Cunha BA. Clinical features of Rocky Mountain spotted fever. Lancet Infect Dis 2008; 8(3): 143-44.

[4] Álvarez-Hernández G, Murillo-Benitez C, Candia-Plata MC, Moro M. Clinical profile and predictors of fatal rocky mountain spotted fever in children from Sonora, Mexico. Ped Infect Dis J 2015; 34(2): 125-30.

[5] Kirkland JE, Wilkinson WE, Sexton DJ. Therapeutic delay and mortality in cases of Rocky Mountain spotted fever. Clin Infect Dis 1995; 20(5): 1118-121.

[6] Masters E, Olson GS, Weiner SJ, Paddock CD. Rocky mountain spotted fever a clinician's dilemma. Arch Intern Med 163(7): 769-74.

[7] Lee N, Lp M, Wong B, Lui G, Yin-Tsang OT, Lai JK, et al. Risk factor associated with life - threatening rickettsial infections. Am J Trop Med Hyg 2008; 78(6): 973-78.

[8] Zientek J, Dahlgreen FS, McQuiston JH, Regan J. Self-reported treatment practices by healthcare providers could lead to death from Rocky mountain spotted fever. J Pediatr 2014; 164(2): 416-18.

[9] Guzmán M and Kouri G. Dengue: an update. Lancet Infect Dis 2002; 2(1): 33-42.Staples.

[10] JE, Breiman RF, Powers AM. Chikungunya fever: an epidemiological review of a re-emerging infectious disease. Clin Infect Dis 2009; 49(6): 942-48.

[11] Saswat T, Kumar A, Kumar S, Mamidi P, Muduli S, Kumar N, et al. High rates of co-infection of Dengue and Chikungunya virus in Odisha and Maharashtra, India during 2013. Infec Genet Evol 2015; 35: 134-141.

[12] Walker DH, Hawkins HK, Hudson P. Fulminant Rocky Mountain spotted fever. Its pathologic characteristics associated with glucose-6-phosphate dehydrogenase deficiency. Arch Pathol Lab Med 1983; 107 (3): 121-5.

[13] Paddock CD, Greer PW, Ferebee TL, Singleton J, McKechnie DB, Treadwell TA, et al. Hidden mortality attributable to Rocky Mountain spotted fever: immunohistochemical detection of fatal, serologically unconfirmed disease. J Infect Dis 1999;
179 (6): 1469-76.

[14] Abarca K, Oteo JA. Aproximaciones clínicas y principales rickettsiosis transmitidas por garrapatas presentes en Latinoamérica. Rev Chilena Infectol 2014; 31 (5): 569-76.

[15] Pialoux G, Gauzere BA, Jaureguiberry S, Strobel M. Chikungunya, an epidemic arbovirosis. Lancet Infect Dis 2007; 7: 319-27.

[16]Rahman-Malik M, Mnzava A, Mohareb E, Zayed A, Al Kohlani A, Thabet AAK, et al. Chikungunya outbreak in Al-Hudaydah, Yemen, 2011: epidemiological characterization and key lessons learned for early detection and control. J Epidemiol Glob Health 2014; 4: 203-11.

[17] Simmons CP, Farrar JJ, Van Vinh Chau N, Wills B. Dengue. N Engl J Med 2012; 366: 1423-32.

[18] Mukkada S, Buckingham SC. Recognition of and prompt treatment for tick-borne infections in children. Infect Dis Clin N Am 2015; 29: 539-555.

[19] De Lara-Huerta J \& Cárdenas-Barragán R. Fiebre manchada de las montañas rocosas en pediatría: revisión clínica de una serie de 115 casos. Rev Enflnfecc Ped 2008; 22 (85): 4-9

[20] Torres JR, Codova LG, Castro JS, Rodríguez L, Saravia V, Arvelaez J, et al. Chikungunya fever: atypical and lethal cases in the western hemisphere a Venezuelan experience. ID cases 2 2015: 6-10.

[21] Delevaux I, Andre M, Colombier M, Albuisson E, Begue RJ, Piette JC, et al. Can procalcitonin measurement help in differentiating between bacterial infection and other kinds of inflammatory processes? Ann Rheum Dis 2003; 62(4): 337-40.

[22] Alkholi UM, Al-monem NA, El-Azim AAA, Sultan MH. Serum procalcitonin in viral and bacterial meningitis. J Glob Infect Dis 2011; 3(1): 14-18.

[23] Raczniak GA, Kato C, Chung IH, Austin A, McQuiston JH, Weis E, et al. Case report: co-infection of Rickettsia rickettsii and Streptococcus pyogenes: is fatal Rocky Mountain spotted fever underdiagnosed? Am J Trop Med Hyg 2014; 91(6): 11541155.

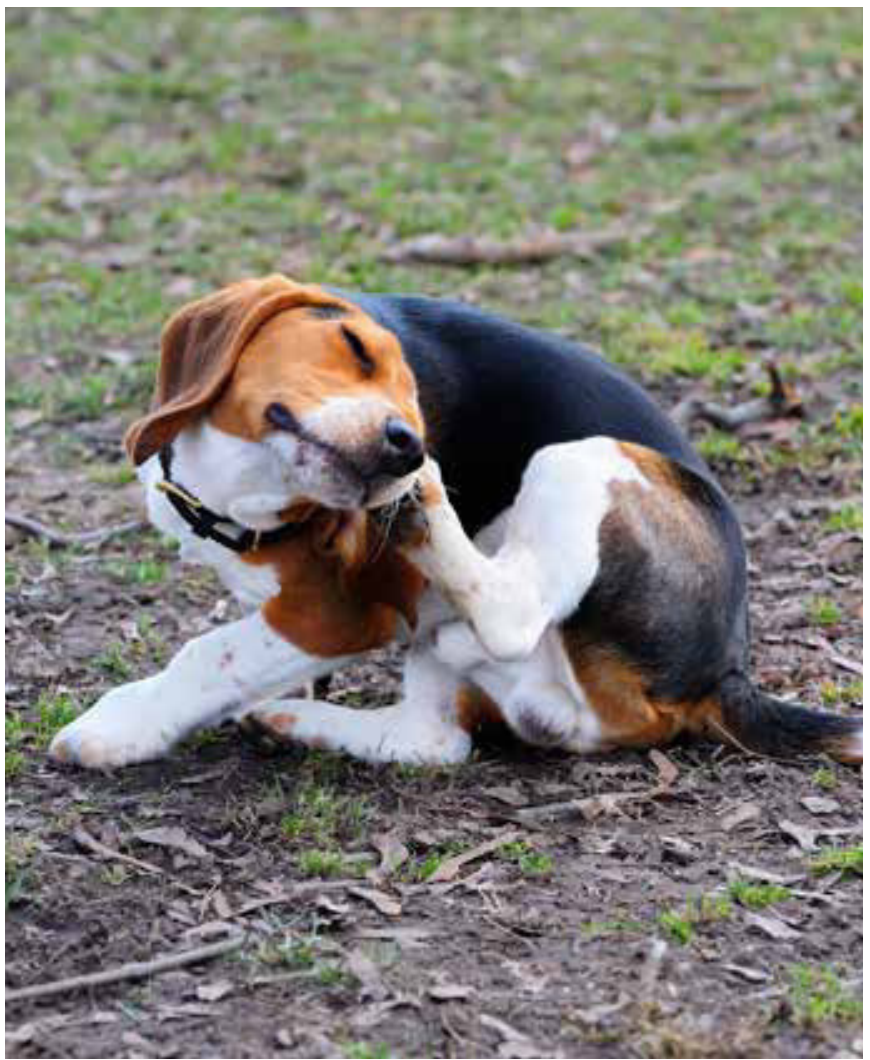

